\title{
Using multiple biomarker parameters to quantitatively unravel mixed oils from different sources: an example from the slope of the Qikou Depression, Bohai Bay Basin, China
}

\author{
L. ZHANG ${ }^{1}$, G. BAI ${ }^{2}$, X. ZHAO ${ }^{3}$, L. ZHOU ${ }^{3}$, S. ZHOU ${ }^{1}$, \\ W. JIANG ${ }^{3}$ Z. WANG ${ }^{1}$
}

${ }^{1}$ Key Laboratory of Petroleum Resource, Institute of Geology and Geophysics, CAS, Beijing 100029, China

(*correspondence: lpzhang@mail.iggcas.ac.cn)

${ }^{2}$ State Key Laboratory of Petroleum Resources and Prospecting, China University of Petroleum, Beijing 102249, China

${ }^{3}$ Dagang Oilfield Company of PetroChina, Tianjin 300280, China

It is difficult to quantitatively unravel mixed oils from different source rocks deposited in similar environments, as concentrations of biomarkers in oils cannot be used directly to estimate the mixing ratios due to secondary alterations of oils. As the the source rocks cannot be distinguished with two or three parameters of biomarker ratios, these parameters cannot reflect the mixing ratios either. In this study, we present a new approach for the computation of the mixing ratios, using the discriminant analysis of multiple biomarker parameters on the basis of differentiating source rocks in multi-variate space. This method was applied to quantitatively unravel mixed oils in the slope of the Qikou Depression in the Bohai Bay Basin. The main source rocks in this depression are developed in the Sha-3 $\left(\mathrm{Es}_{3}\right)$ and Sha-1 $\left(E_{1}\right)$ Members of the Paleogene Shahejie Formation, and cannot be distinguished with several biomarker ratios due to similar sedimentary environments. But the discriminant model with 22 parameters of biomarker ratios achieved a high correct rate of leave-one-out cross-validation (91.4\%), indicating a sufficient differentiating and discriminant power. The computation results obtained from this discriminant model illustrate that $42 \%(30 / 71)$ of oils are mixed ones from the two source rock intervals in $\mathrm{Es}_{3}$ and $\mathrm{Es}_{1}$ (mixing ratios from $10 \%$ to $90 \%), 44 \%(31 / 71)$ mainly derived from $\mathrm{Es}_{1}$ and $14 \%(10 / 71)$ from $\mathrm{Es}_{3}$ (mixing ratios for the oils from the other source $<10 \%$ ). The mixed oils are distributed along deep-large fault belts, illustrating that the oil mixing resulted from secondary migration through the fault planes. The computation results of the mixing ratios together with the assessment of the petroleum resouce further reveal that there is still a significant exploration potential in the Sha-3 petroleum system in the slope of the Qikou Depression. 